\title{
Force Sensor for measuring interaction forces of cardiologists during heart catheterizations
}

\author{
T. Opitz, A. Sacakli, N. Stefanova, T. Rossner, T. Meiss, R. Werthschützky \\ Technische Universität Darmstadt, Institute of Electromechanical Design, \\ Merckstr. 25, 64283 Darmstadt, Germany \\ E-Mail: t.opitz@emk.tu-darmstadt.de
}

\begin{abstract}
:
This paper describes the development of a uniaxial force sensor for measuring interaction forces of a cardiologist. The technical challenges are limited construction volume inside the torque device, feed through of the guide wire through the force sensor and maintaining the standardized fixing mechanism of the guide wire. A force sensor is presented, which is capable of measuring forces from $-10 \mathrm{~N}$ to $10 \mathrm{~N}$. Resistance strain gauges are used in full bridge alignment to compensate temperature drifts. The deformation element is made out of steel (SR275). The outer diameter of the force sensor is $5 \mathrm{~mm}$, the length is $14 \mathrm{~mm}$. The integration into the torque device is shown. Measurements show a non-linearity of $1.3 \%$ and a hysteresis of $2.8 \%$. The measurement uncertainty is $3.88 \%$.
\end{abstract}

Key words: medicine, haptic, uniaxial, resistive

\section{Introduction}

Conventional navigation during heart catheterizations is done by direct manipulation of a torque device (Fig. 10) at the proximal end of a guide wire, which acts as guidance for the catheter. Its diameter is 1 French, which is equivalent to $360 \mu \mathrm{m}$. With the aid of x-ray imaging the corresponding movement of the guide wire's tip in the patient's vascular system can be monitored visually. Other human senses are not involved into the procedure and so cardiologist's perception is reduced while navigating through the blood vessel system. Within the HapCath - project (Institute of Electromechanical Design, Technische Universität Darmstadt) a haptic assistance system for interventional heart catheterizations is developed (Fig.1). It provides a haptic feedback by measuring the contact forces at the guide wire tip [1] and feeding them back onto the proximal end of the guide wire to improve the force feedback presented to the cardiologist. The force feedback is generated by an extracorporeal electrodynamic haptic interface [2],[3]. The benefits of a haptic assistance system for heart catheterizations are:

- Multimodal information (visual and haptic) about the environment at the distal tip of the guide wire can reduce the cognitive load of the cardiologist.
- The dosage of $x$-rays and contrast media can be reduced.

- Palpation of stenosis and stents for diagnostic purposes

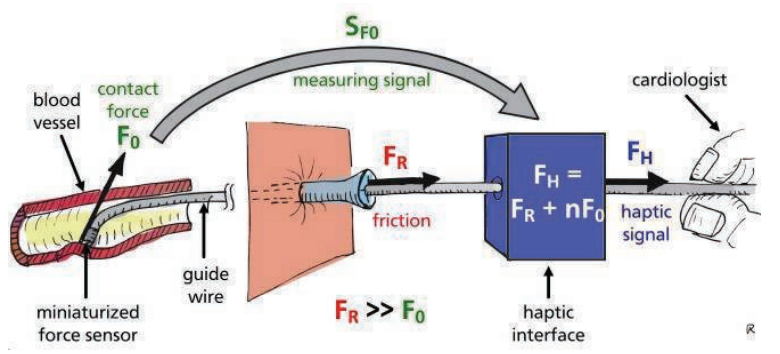

Fig. 1: Schematic representation of the haptic assistance system HapCath.

So far the system works in open loop control. The motor current is proportional to the measured force at the guide wire tip. Because of varying friction within the patient's vascular system performance and stability of the system is strictly limited. To overcome these deficits, measuring interaction forces at cardiologist's fingertips and a closed-loop control of the HapCath-system is advisable. This paper describes the development of a novel sensor for measuring interaction forces at cardiologist's fingertips and the integration into a torque device. 
The following section describes the measuring principle of the force sensor and presents an analytical model as well as simulation results. Thereafter the integration of the force sensor into a torque device is shown. The paper closes with results and conclusion.

\section{Concept and design}

The force sensor must measure axial forces from $-10 \mathrm{~N}$ to $10 \mathrm{~N}$. It must be able to measure static and dynamic forces. The overload resistance must be greater than $20 \mathrm{~N}$. The outer diameter must not exceed $5 \mathrm{~mm}$ and the sensor must contain an axial feed through for the guide wire.

For this sensor, the resistive measuring principle is selected. The resistive principle ensures a good potential of miniaturization, a low disturbance sensitivity and good resistance against fluids and contamination.

The basic design of the force sensor is shown in Figure 2. The axial force is applied on the deformation element and guided by two Ushaped bending beams. The strain gauges are mounted in section II of the bending beam. It is used 4 strain gauges in a full bridge. To determine the sensor output signal $u_{a}$ the mechanical tension and strain in the deformation element has to be calculated. The mechanical tension $T$ in a beam with the crosssectional width $b$ and the section height $h$ is given by

$T(x, z)=\frac{N(x)}{A(x)}+\frac{M_{y}(x)}{l_{y}(x)} z$.

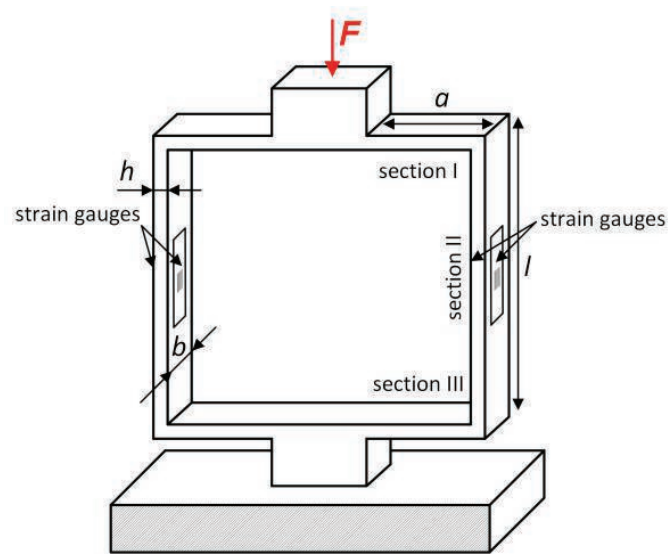

Fig. 2: Basic design of the force sensor.

Thus, the internal forces $N(x), M_{y}(x)$ of the beam structure are to be determined. In Figure 3 the mechanical model for one bending beam of the sensor is shown. The lower clamping is the foundation of the force sensor. The upper clamping is displaceable along the central axis. Since the system is two-fold statically

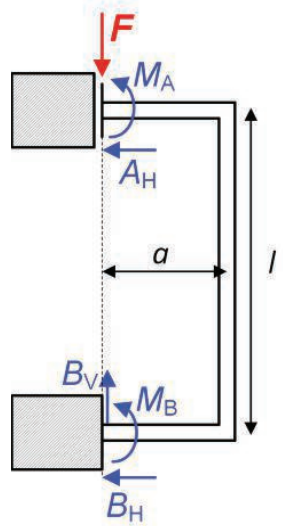

Fig. 3: Two-fold statically indeterminate mechanical model of one bending beam structure.

indeterminate, the principle of virtual forces is used to determine internal forces $N, Q, M[4]$.

For this, the statically indeterminate system is made statically determined by removing two bearing reaction forces and replacing them by two virtual forces respectively moments. Thereafter the internal forces of the resulting statically determined system are calculated for the external force $F$ and the two virtual moments $X_{\mathrm{A}}, X_{\mathrm{B}}$ (Fig. 4). Using a linear equation system, the strain energy of the real and virtual forces is coupled. With the constraints of the origin indefinite system all bearing reactions are finally calculated and the real internal forces can be determined.

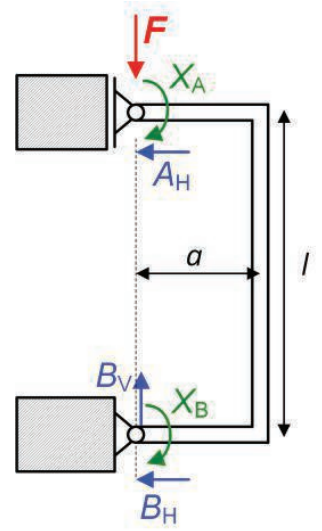

Fig.4: Statically determinate mechanical model of one bending beam structure with two virtual moments $X_{A}$ and $X_{B}$.

Thus, it applies for the mechanical tension $T$ in section II of one bending beam

$$
\begin{aligned}
& T(F, x, z)=-\frac{F}{2 b h} \\
& F a-\frac{3 F h^{2} f^{2} \cdot\left(a^{2}+a l\right)\left(\frac{12\left(a+\frac{1}{3}\right)-2 a}{h^{2}}+\frac{4 a}{h^{2}}\right)}{2 r^{2}\left(36\left(a+\frac{1}{3}\right)^{2}-a^{2}\right)+h^{2}\left(24 a\left(a+\frac{1}{3}\right)+4 a^{2}\right)} \\
& b h^{3}
\end{aligned}
$$


The bridge output voltage is given by

$u_{\mathrm{a}}=\frac{R_{2} R_{4}-R_{1} R_{3}}{\left(R_{1}+R_{2}\right)\left(R_{3}+R_{4}\right)} u_{0}$

and for each strain gauge applies

$R_{\mathrm{i}}=R_{0}\left(1+\mathrm{k} S_{\mathrm{i}}\right)$.

Whereby the strain is calculated by

$S_{\mathrm{i}}=\frac{T_{\mathrm{i}}}{\mathrm{E}}$

Taking into account the constraints

$S_{1}=S_{3}=T\left(F, X, Z=\frac{h}{2}\right)$
$S_{2}=S_{4}=T\left(F, X, Z=-\frac{h}{2}\right)$

and the equations from (3) to (5) it follows

$u_{\mathrm{a}}=\frac{\left(1+\mathrm{k} S_{2}\right)^{2}-\left(1+\mathrm{k} S_{1}\right)^{2}}{\left(\left(1+\mathrm{k} S_{1}\right)+\left(1+\mathrm{k} S_{2}\right)\right)^{2}} \cdot u_{0}$

\section{Simulation}

The design of the deformation body is optimized with the Finite element method (FEM) [5]. FEM is useful to check the validity of the analytical model. Furthermore peak stresses in the deformation element can be analyzed and reduced by iterative optimization.

Figure 5 shows the basic design and the optimized model of the deformation element.

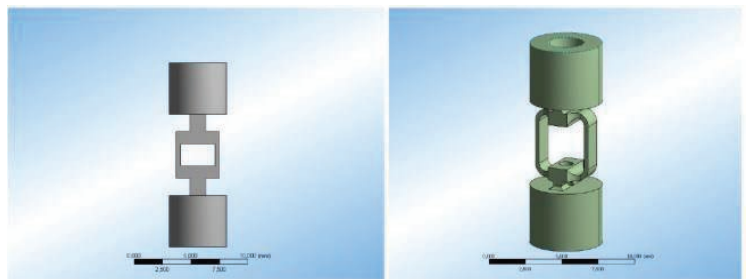

Fig. 5: Basic design (left), final design (right) [5].

The simulation results for pressure and tensile deformation of the deformation element are shown in Figure 6 and 7. The maximum stress at a nominal force of $10 \mathrm{~N}$ is $98.23 \mathrm{MPa}$. The maximum yield strength is $275 \mathrm{MPa}$ (steel SR275). The sensor is thus overload protected up to $28 \mathrm{~N}$.

\section{Integration into torque device}

The torque device with integrated force sensor is shown in Figure 10. The force is applied by a chuck, which fixes the guide wire by friction. The grip bush is guided by a bush bearing made out of Teflon and is secured against

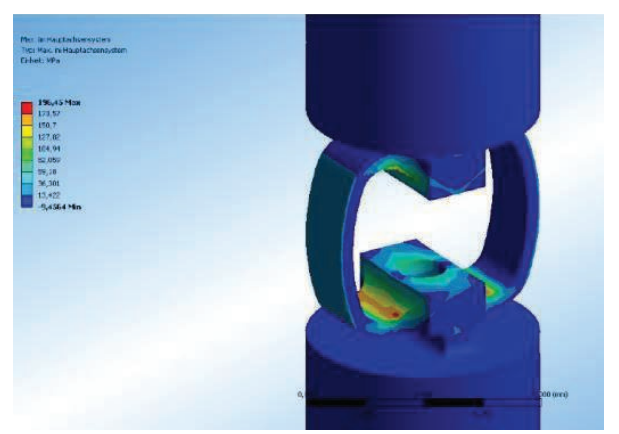

Fig. 6: FEM simulation, pressure [5].

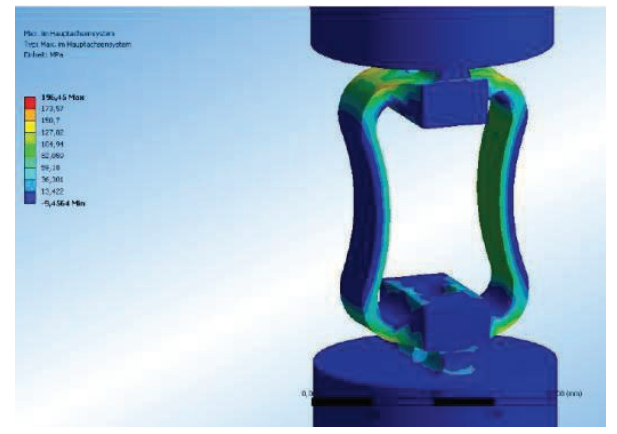

Fig.7: FEM simulation, tensile [5].

twisting. The outer diameter of the torque device with force sensor is $8 \mathrm{~mm}$ and the length is $43 \mathrm{~mm}$.

\section{Measurement results}

The measurement setup is shown in Figure 9. The force is applied, as in the case of application over a wire. For this purpose, a stainless steel wire is used with the same diameter as a guide wire $(360 \mu \mathrm{m})$. The second point of force application is at the bush and thus corresponds to the handle situation of a cardiologist. The control of the applied force and the recording of the measured data are done in LabVIEW. The measuring range is -10 to $10 \mathrm{~N}$. A total of 20 measurement cycles with 20 power levels for each cycle are recorded after a run-in phase. 10 datasets are taken on each load stage. Thus, there are 200 recorded datasets for each power stage. The static characteristics (Fig. 8) show a good linearity and low hysteresis. Table 1 summarizes the calculated sensitivity for the analytic model and the simulation compared to measurement results. The results show a good compliance of analytic model and simulation. The deviation of theoretical calculated and measured sensitivity is due to manufacturing tolerances. Height $h$ is $420 \mu \mathrm{m}$ instead of $300 \mu \mathrm{m}$. The non-linearity is $1.3 \%$ and the hysteresis is $2.8 \%$. The random error is $2.35 \%$. Therefore the measurement uncertainty of the force sensor is $3.88 \%$. 
Tab. 1: Comparison of analytic model, simulation and measurement

\begin{tabular}{|c|c|c|c|c|}
\hline & \multicolumn{2}{|c|}{ strain } & \multirow{2}{*}{$\begin{array}{c}\text { sensitivity in } \\
\mathrm{mV} / \mathrm{N}\end{array}$} & \multirow{2}{*}{$\begin{array}{c}\text { deviation in } \\
\%\end{array}$} \\
\hline & inner side & outer side & & \\
\hline nalytic & $-1,99 \cdot 10^{-4}$ & $8,60 \cdot 10^{-5}$ & 0,570 & - \\
\hline simulation & $-2,03 \cdot 10^{-4}$ & $8,29 \cdot 10^{-5}$ & 0,572 & $0,35 \%$ \\
\hline measurement & - & ( & 0,301 & $-47,03 \%$ \\
\hline
\end{tabular}

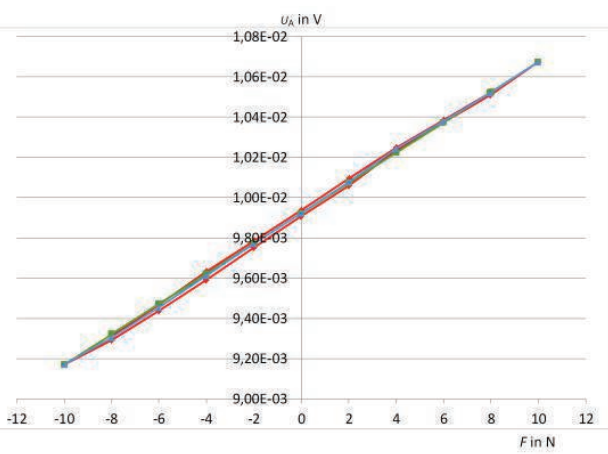

Fig. 8: Static characteristic curve.

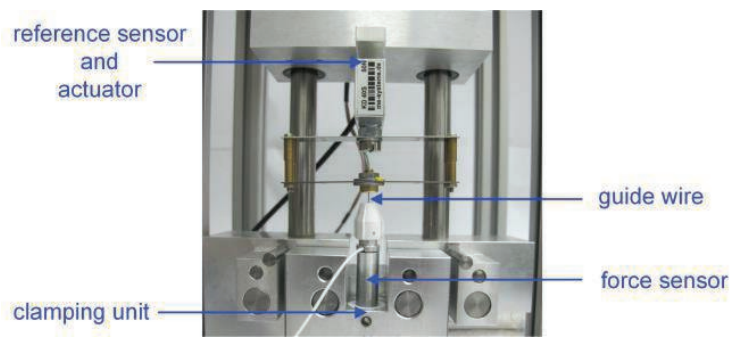

Fig.9: Measurement setup.

\section{Conclusion}

This paper shows concept and design of an extracorporeal force sensor for heart catheterizations. A mathematical model is given and simulation results are presented. The metrological characterization of the force sensor indicates that the developed and constructed sensor meets the requirements for extracorporeal measurement of interaction forces during heart catheterizations and thus is suitable for use in the haptic assistance system HapCath. With an adjustment of the production technology manufacturing tolerances can be reduced.

Furthermore, the sensor can be easily adapted so that it can cover a bigger or smaller measurement range.
By the use of piezoresistive strain gauges, the sensitivity of the sensor can be increased and a smaller measurement range can be obtained with the same overload resistance.

In addition the force sensor is also suitable for other applications such as:

- miniaturized linear actuators,

- parallel kinematics,

- measurement of rope forces.

\section{Acknowledgment}

The authors appreciate the support of the Deutsche Forschungsgemeinschaft (DFG) to run this project (WE 2308 / 15-03).

\section{References}

[1] Meiss, T.: Konstruktion eines Mikrokraftsensors für Herzkatheterisierungen. Institute of Electromechanical Design, Dissertation, TU Darmstadt, 2012, Darmstadt

[2] Opitz, T.; Neupert, C.; Werthschützky, R.: Development of a Haptic Assistive System for Force Transmission onto a Guide Wire. Actuator 2012, $13^{\text {th }}$ International Conference on New Actuators, 18-20 June 2012, Bremen, Germany

[3] Opitz, T.; Neupert, C.; Rossner, T.; Stefanova, N.; Meiss, T.; Werthschützky, R.: Miniaturized Haptic User-Interface for Heart Catheterizations - Concept and Design. In: Biomedical Engineering / Biomedizinische Technik, September 2013, Graz, Austria

[4] Adam, J.: Festigkeitslehre und FEMAnwendungen: Grundlagen der Festigkeitslehre und Einführung in die Anwendung der Finite Elemente Methode. 1991 Hüthig Buch Verlag, Heidelberg

[5] Sacakli, A.: Entwicklung eines strukturintegrierten Kraftsensors für haptische Assistenzsysteme. Institute of Electromechanical Design, Bachelor Thesis, TU Darmstadt, 2013, Darmstadt

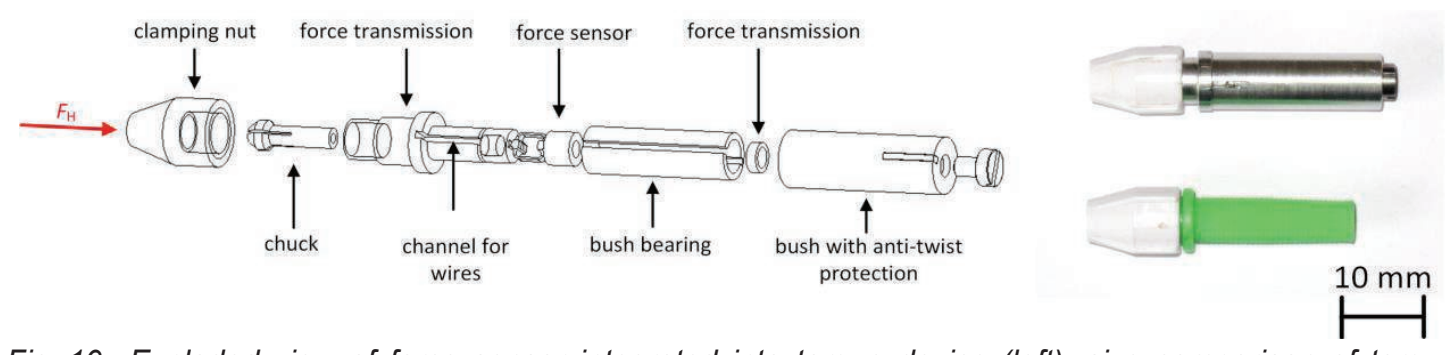

Fig. 10. Exploded view of force sensor integrated into torque device (left), size comparison of torque device with integrated force sensor and standard torque device (right). 